\title{
The Relation between Ethics and Law according to the Doctor's Malpractice in Improving the Healthcare Quality in Jordanian Government Hospitals
}

\author{
Okour. Mohammad-Noor Said Deeb ${ }^{1}$, Okour. Karim Saeed ${ }^{1}$, \\ Melhem. Shefaa Mustafa ${ }^{2}$, Ndjiembi A. Christiane ${ }^{1}$ Zhanchun Feng $^{1 *}$ \\ ${ }^{I}$ Medicine and Health Management School, Tongji Medical College, Huazhong University of Science and \\ Technology, 13 HangKong Rd. , Wuhan, Hubei 430030,China . \\ ${ }^{2}$ Jordan ,Irbid , Al- yarmouk university
}

\begin{abstract}
The few available data that exist show that the nature relation between ethics and law according to the doctor's malpractice in improving the health care quality. This research aims to perform a comparative analysis for Jordanian government hospitals depending on the relation between ethics and law according to the doctor's malpractice to find out the main problems and factors that influence on improving the health care quality for Jordanian government hospitals and then recommend solutions for these problems. A sample of 100 doctors (81 males and 19 females) aged 18-60 years was selected from four departments; maternity, surgery, medical and pediatric using a systematic random sampling technique. Results demonstrated that around $92.0 \%$ of respondents agreed that the malpractice of doctors has major influence on the quality of health care. The majority of the respondents explored that this problem can be minimized based on applying the law, while other respondents related this problem to their ethics. Concerning the occurrence of medical errors, respondents verified that the main two reasons behind these errors are the patients and low experience of doctors. On the other hand, results showed that doctors have inadequate information about malpractice and its effect on the health care quality. Thus, to reduce the malpractice of doctors in government hospitals specifically, ministry of health should put strict laws and monetary fines for doctors to decrease the proportion of malpractice in those hospitals.
\end{abstract}

Keywords: ethics, health care quality, law, malpractice, patients, practice

\section{Research Question}

\section{Introduction}

The main question of this article is: what is the relation between ethics and law according to the doctor's malpractice in improving the health care quality in Jordanian government hospitals?

According to the main research question, the main points that must be considered in this research are:

- Doctor's malpractice and its effect on health care quality.

- The reasons behind doctor's malpractice and its relation to the ethics and the law.

- The effect of ethics and the law in improving the doctor's malpractice and the quality of health care.

\section{Medical malpractice Overview}

Medical malpractice represents the errors or omissions caused by doctors or other medical professionals, which leads to patient injury. As specified by the legal systems, omissions or errors that do not cause injuries for patients are not related to "malpractice" because the elements of causation and injury are missing. In general, the determination of an error or omission is based on the deviation of doctors or medical professionals from the acceptable level of care. Whereas an injury that is result from medical treatment is not considered as "malpractice" [1].

Medical malpractice-neglect and irresponsibility of both hospitals and physicians cause injures hundreds for thousands of people each year. In 2000, the Institute of medicine published a lengthy report concerning that "To Err Is Human" and demonstrated that medical errors cause up to 98,000 deaths in hospitals annually [2]. Unfortunately, lawmakers and stakeholders have majorly focused on limiting the liability of those errors without finding solutions to reduce them. As a result, a study was published on July 2004 and demonstrated that two-thirds of states were applied "measures of repair damage" which limit or restrict the lawsuits for medical malpractice; there was no improvement in the field of safety, where the number of avoidable deaths in hospitals only is approximately 195,000 per year, excluding the obstetrics patients [3].

In spite of these statistics, when organizations discuss the malpractice "crisis," they refer to the injured or killed people by medical errors or the widespread failure to discipline neglect physicians, including repeat 
The Relation between Ethics and Law according to the Doctor's Malpractice in Improving ...

offenders, but doctors' alternatively increase malpractice insurance premiums [4]. "Lobbyists" who seeking to repair the damage, in order to reduce the victim's rights of medical malpractice, about health care that is unrelated to, or would not be addressed by the reforms they seek. Particularly, the insurance industry repairs the damage proponent depending on both the misinformation and the large extent anecdotal evidence that the civil justice system is "out of control" and needs to be reduced [5].

However, facts reveal a different picture. There civil justice system has various checks and balances to discourage trivial suits and punish those who file them [6]. In order to fully understand whether the U.S. medical malpractice system is achieving one of its stated fundamental goals, it is important that a malpractice researcher gives independent evaluation for health care quality issues. Therefore, whether the goal is to make an independent assessment of the deterrent impact of medical liability or to distinguish between deterrence and a defensive response to liability, it is necessary to estimate the effect of the malpractice system on both medical errors and health care quality.Evidence suggests that medical errors still occur with increasing rates where this indicates that the health care quality is at undesirable levels [7].

Medical malpractice, carelessness and negligence of doctors and hospitals cause the death of a lot of people every year. Unfortunately, legislators have completely focused on the reduction of the responsibility of those mistakes that can be prevented regardless the reduction of their occurrence. However, the number of medical malpractice cases dropped over the past ten years. Great majority of those infected by malpractice is not complaining in order to Legal accountability. The number of deaths that can be avoided in hospitals is now around 195,000 per year, excluding birth patients. Conversely, with considering certain malpractice crisis, such as the "American Medical Association" (AMA) organizations, do not focus on the injured or killed people by medical errors or failures in large scale to discipline neglect doctors (including repetition criminals), but on the doctors' malpractice for increasing insurance premiums [8].

\section{Medical malpractice laws in Jordan}

The current system in Jordan which addresses medical malpractice troubles has a number of shortcomings. Practically, most of the surrounding countries have not a legislation that directly addresses the medical malpractice. Instead, malpractice claims are decided based on general laws which deal with damages. These laws provide little guidance in the adjudication for complex cases of medical malpractice. Claims are subjected to a lengthy court procedure (the average duration of a civil case in a court of first impression is 534 days; where $40 \%$ of decisions are appealed). Judges usually have inadequate experience with respect to medical issues. Expert opinions are reportedly often based on the favor of the medical service providers [1].

Jordan follows a "fault" or "tort" system to determine the damage awards for medical malpractice. Article 256 of the Civil Code explored that "Every act causing damage to others obliges its perpetrator to pay damages". Jordanian courts have reported that the "act" which causes injury is the act that deviates from the expected normal action/performance from ordinary and reasonable persons [1].

"Damages awarded" may include physical damages (such as damages to the person's body), economic damages (such as paying for medical expenses and loss of income) and moral damages (such as damage to reputation and mental health). The claimant must prove that damages were caused by this act, and it was not coincidence or the irregularities from third persons or by the claimant himself [1].

In Jordan, medical malpractice claims may also be pursued under the criminal law. Small financial penalties are in criminal cases, but doctors and other medical staff may be subjected to prison sentences. An increasing number of criminal cases have been filed; it seems as a way to force defendants to settle outside of court to avoid public notoriety, mandatory attendance at court proceedings, and the possibility of significant prison sentences [1].

Jordan applies the rule of joint and several liabilities, but the general rule under Jordanian law is that a person is not responsible for someone else action unless the person maintains supervisory or controls authority over the person who is primarily responsible for the injury. Civil claims must be submitted during three years from the date of discovering the basis for the claim. Lawyers in Jordan are allowed to enter into emergency fee contracts, as long as the emergency fee does not exceed $25 \%$ of the refund amount. In addition, courts may include the legal fees of the winning party in a damage award [1].

Practically, few medical malpractice claims have been followed in Jordan. Judges estimate that less than 10 cases per year are filed as well as the compensation for damage is reportedly low. Some of these claims have been settled by mediation. Insurance for medical malpractice is not generally available and the few policies that are issued are financed by foreign insurers companies [1].

\section{Laws, ethics and health care quality in medicine}

All states must follow the rules and laws in practice during everyday tasks. They should also follow both ethical issues and medical law during medical practice according to the "American Association of Medical Assistants" (AAMA) law of ethics. Furthermore, states must follow the law to avoid lawsuits that filed against 
The Relation between Ethics and Law according to the Doctor's Malpractice in Improving ...

doctors because of the wrong practices of physicians in the diagnosis or treatment of some patients. All medical offices should include the whole regulations of the "Occupational Safety and Health Administration" (OSHA) for safety toxic substances and dangerous equipment's to help doctors effectively. Furthermore, they must include instructions control and quality assurance for all samples, treatments and tests. Patient records must be kept in an orderly and easily accessible way to maintain the confidentiality of patient records and patient privacy, with following the "Health Insurance Portability and Accountability Act" (HIPAA) instructions [9].

Doctors mainly react with medical liability systems regardless of the type of pressure that they are exposed to, whether with cardiac procedures or regional obstetric cases. This varies according to the followed law of malpractice in various regions. But, this does not mean that the work is done properly, since it should encourage medical practices with high quality and provide better care for patients. In few words, medical goals can be correctly achieved when doctors effectively respond to the law of malpractice. Guidelines are designed to encourage greater efficiency in terms of cost and maintain the quality of medical practices [9].

Doctors can response for "malpractice standards", but that liability may only lead for deterrence from "low quality practices" and medical errors, nevertheless these responsibility standards are the same designed to guarantee such this result. Nowadays, to determine the expected standards for doctors, the responsibility system are largely related to the medical custom itself according to the law (in contrast, a more abstract process of determining what reasonable and proper care is). The results for a current malpractice system that does not effectively improve the quality of care, that delivered by medical providers with a focus on compound measures of "Health care quality" in both "inpatient and outpatient" domains [10].

Early, the patients do not aspired little information about the quality of medical care. One method of law seeks to work around this information issue, by allowing for infected patients to benefit from a provider of health care via procedures against medical negligence. The rules that determined the responsibility for medical malpractice by the legislatures and courts are standardized within the state. Medical system malpractice requires protecting all patients with the same level. There is almost universal accord that the system of medical malpractice does not bring its goals [11].

"Quality Improvement" (QI) takes one approach from all approaches reform in any companies where it is driven particularly by study group. It refers to large occurrence of medical errors and a striking absence of harmonization in the provided care level to patients in different facilities and from different staff of centers. At the national level, rapid changes in the field of health care motivate organizations to move "Quality Improvement" (QI) activities from a project level to an organization-wide one improve both the patient safety and cost containment and link reimbursement incentives directly to execute better knowledge in this time. Each of these changes requires "Quality Improvement" (QI) activities [12].

Best practices international concludes that programs of insurance established by the defense of medical organizations and cooperatives doctors are forms that must be considered. It should be also considered in the insurance of first party for medical tourists. The development of a new medical malpractice claims order by the Kingdom of Jordan on the basis of international law "best practices" will benefit both medical tourism and Jordanian citizens who have medical malpractice claims. In addition, the quality of health care will be enhanced through the adoption and implementation of medical standards and the improvement of medical records [1].

The "Quest for Quality and Improved Performance" (QQUIP) is an initiative research for a period of five years from the health association. QQUIP provides reports independently on broad range statements about the performance and quality of health care. It is based on the international guide bases for the production of information on the location and is currently spent health care resources, whether they supply value for the money or not and how interventions have been used all over the world in order to improve the quality of health care [13].

Doctors are the backbone of health care sector. However, their behavior is still a major goal of government regulation, which aims to improve the quality, efficiency, and ease of access to health care. Stimulation, deter, and guidance conduct doctors across a broad range of activities, including the main elements of the relationship between doctor and patient. In order to detect and punish dissident doctors and so monitor the conduct of doctors over the past few decades. The objective of this effort is performing material change in the relationship between the doctor-patient relationship and medicine to the marketplace. Demand physicians, the law aims to improve of the health of their patients rather than making doctors provide poor care [14].

The "bad law" claims have often fallen by the reform effort itself. Changes aim to transfer the relationship between doctors and patients to a fairer model, whether through the legal obligation of informed consent or through removing the legal barriers that impede market operation where in this case, the traditional claims of professionalism must be weakened or rejected. Legal and political efforts over the past few decades have dismantled the traditional claims for medical professionalism about the relationship between medicine and law [14]. 


\section{Study design, sampling and procedure}

\section{Methods}

This cross-sectional survey was conducted between the $1^{\text {st }}$ and $16^{\text {th }}$ February, 2014 in five government hospitals in Jordan. Private hospitals were excluded from the study since their medical systems are more reliable in comparison with those of government hospitals. Those five government hospitals were chosen purposively in two Jordanian cities because both have more government hospitals than other cities. A total of 100 male and female doctors, aged 18 - 60 years were asked to participate in this survey. The sample size was calculated based on the estimate that $50 \%$ of doctors may have enough knowledge on malpractice in their jobs. The precision, $\mathrm{P}$ value and power of the study were set to $10 \%, 0.05 \%$ and $80 \%$, respectively, where the expected sample size was 50 doctors. The aim was to recruit 100 respondents. To obtain the desired target of this sample, it was decided to choose 24 doctors from pediatric department, 24 doctors from medical department, 25 doctors from surgery department and 27 doctors from maternity department using a systematic random sampling technique.

\section{Questionnaire}

The aim of the questionnaire was to obtain information concerning the malpractice level of respondents and the relation between ethics and law to decrease these malpractices in order to improve the health care quality in the government hospitals. The questionnaire was developed by certain researchers in consultation with experts in the field. The final questionnaire included questions related to malpractice of doctors, attitudes toward these malpractices and law that addresses these malpractices, doctor's ethics, and socio-demographic information. The questionnaire was divided into four parts. Part I focused on the socio-demographic characteristics of respondents, including age, gender, department name, experience, educational level, number of training course, place, social status and language for participants. Part II contained 11 questions on malpractice of doctors, with questions related to malpractice, their impact on the health care quality, inexperience role in increasing the proportion of medical errors and causes of malpractice.

Part III comprised 9 questions on law that addresses these malpractices, which again included both positively and negatively framed questions. Part IV comprised 10 questions about ethics of doctors in their job. Before collecting the main data, the questionnaire was piloted with 15 doctors to test the clarity, feasibility and appropriateness of questions for doctors. The questionnaire was developed and tested in both languages; Arabic and English. In this research, "Likers 5 points scale" was used between 1 (strongly disagree) and 5 (strongly agree).

\section{Ethics statement}

Before collecting data, doctors were informed about the purpose of the study and the used technical terminologies in the questionnaire, as well as they were given a guidance concerning how to fill the questionnaire. The trained research assistants distributed the self-administered questionnaire during the 60 minutes break. Doctors were notified that their responses would be kept confidential where they were not required to write their names on the questionnaires. Respondents were also informed that their participation was completely voluntary as well as they were free to decline answering any question. On the other hand, a written informed permission was obtained from all doctors. Furthermore, a prior permission was obtained from the managers of the involved government hospitals to conduct this study. Moreover, this study was approved by the Jordan health sciences research committee, ministry of health.

\section{Statistical analyses}

Data were entered into a spreadsheet and exported to Statistical Package for the Social Science (SPSS) for Windows, version 15.0 software (SPSS Inc., 2001. All rights reserved) to be analyzed. Descriptive statistics were used to describe demographic characteristics about the relation between ethics and law according to the doctor's malpractice in improving the health care quality in Jordanian government hospitals. Numbers and percentages were used to present categorical data. Furthermore, the mean and Standard Deviation (SD) was used for normally distributed continuous data, while the median was used for non-normal continuous data. All tests were two-tailed, where the acceptable level of $\mathrm{P}$ value in this case is 0.05 .

When was entering the socio-demographic characteristics for the respondents to SPSS. Answers for each question were entered as numbers. To evaluate malpractice of doctors, law that addresses these malpractices and ethics of the respondents, doctors were asked to choose "strongly agree", "agree", "neutral", "disagree" or "strongly disagree" for each question. Whereas scores were assigned as 1 for "strongly disagree" answers, 2 for "disagree" answers, 3 for "neutral" answers, 4 for "agree" answers and 5 for "strongly agree" answers. Finally, scores were summed up to generate an overall score for each participant. 


\section{Socio-demographic characteristics}

\section{Results}

According to the age factor of the participants, 39.0 percent of the participants aged 26-35 years. On the other hand, 26.0 percent of participants aged 36-45 years, 20.0 percent of them aged 18-25, while 15.0 percent of them aged above 46 . This means that most of the participants were aged 26-35 years. Concerning the education degree factors, $50 \%$ of respondents have bachelor degree, $35.0 \%$ of them have Master degree, while the residue have $\mathrm{PhD}$ degree. Concerning the number of taking training courses by doctors, around 73.0 percent of the participants had taken one training course, 26.0 percent of them had taken 1 to 3 courses, while 1 percent of them taken 4 courses.

Regarding to the number of medical staff in the health care facilities, around21.0 percent of participants have 1-3 medical staff members, 42.0 percent of them have 4-7 medical staff members, while only 13.0 percent of them have 8-10 medical staff members. The residue of participants has above 10 medical staff members. According to the number of checked patients daily by the participated doctors in this survey, 11.0 percent of those doctors check 1- 10 patients daily, 16.0 percent of them check 10-20 patients per day, while 24.0 percent of them check 20-30 patients every day. The residue of the participants stated that they check above 30 patients each day. (Table 1) below show the other socio-demographic characteristics.

\begin{tabular}{|c|c|c|}
\hline Variable & Number & $\%$ \\
\hline \multicolumn{3}{|l|}{ Gender } \\
\hline Male & 81 & 81.0 \\
\hline Female & 19 & 19.0 \\
\hline \multicolumn{3}{|l|}{ Department name } \\
\hline Maternity department & 27 & 27.0 \\
\hline Surgery department & 25 & 25.0 \\
\hline Medical department & 24 & 24.0 \\
\hline Pediatric department & 24 & 24.0 \\
\hline \multicolumn{3}{|l|}{ Experience } \\
\hline Less than one year & 18 & 18.0 \\
\hline From $1-5$ years & 38 & 38.0 \\
\hline $6-15$ years & 24 & 24.0 \\
\hline More than 15 years & 20 & 20.0 \\
\hline \multicolumn{3}{|l|}{ Educational level } \\
\hline Bachelor & 50 & 50.0 \\
\hline Master & 35 & 35.0 \\
\hline $\mathrm{PhD}$ & 15 & 15.0 \\
\hline \multicolumn{3}{|l|}{ Place } \\
\hline City & 65 & 65.0 \\
\hline Village & 25 & 25.0 \\
\hline Urban & 10 & 10.0 \\
\hline
\end{tabular}

\section{Malpractice of doctors}

Based on studying the impact of malpractice on health, it was found that the majority of medical providers agreed with the fact that malpractice affects the quality of health care. This issue was analyzed based on the departments of the health workers. Results demonstrated that $52.0 \%$ of the maternity department respondents strongly agreed that the malpractice has an effect on the health care quality. In the surgery department, $44.0 \%$ of respondents agreed with this issue. On the other hand, the medical department had the highest rate of those who strongly agreed with the proposed issue. The table below presents results of data about how malpractice effects on the quality of health care quality.

Table 2: doctor's malpractice of the study population $(\mathrm{N}=100)$.

Questions with strongly agree and agree answers

Your malpractice is effect on health care quality in your job.

If you apply the law in your job, it will decrease your malpractice.

Your malpractice is related with your ethic.

Your Inexperience will increase the proportion of your medical errors.

Medical errors more than deadly for people from road accidents

Number \%

$71 \quad 71.0$

$69 \quad 69.0$

$38 \quad 38.0$

$71-71.0$

$43 \quad 43.0$

The most important causes of medical errors are the lack of the necessary coverage for doctor's beginner or experienced few.

7171.0

Can you differentiate between medical error and medical negligence?

There payment of compensation to people affected by your malpractice in your work.

Your mental greatly effect on your work, especially on your malpractice that can be occur.

Sometimes the patient is the reason for your medical error.

There is a certain number of disabilities were produced due to your medical malpractice.

$\begin{array}{ll}78 & 78.0 \\ 54 & 54.0 \\ 64 & 64.0 \\ 63 & 63.0 \\ 49 & 49.0\end{array}$




\section{Law that address these malpractices}

Concerning the views of health workers on the issue of applying the law and its effect on malpractice, $52.0 \%$ of the maternity department respondents strongly agreed that the application of the law can decrease the malpractice problem. The minority of the surgery department respondents disagreed with this issue. On the other hand, $63.0 \%$ of the respondents from the pediatric department agreed that application of law can effectively solve the problem of malpractice. The table below presents results of data about law and how addresses this malpractice to improve the quality of health care quality.

Table 3: law that address these malpractice of the study population ( $N=100)$.

\section{Questions with strongly agree and agree answers}

Your malpractice is related to the law.

The law in your work will have an effect on the health care quality in your hospital.

$\begin{array}{cc}\text { Number } & \% \\ 55 & 55.0 \\ 83 & 83.0 \\ 48 & 48.0 \\ 67 & 67.0 \\ 37 & 37.0 \\ 54 & 54.0 \\ 52 & 52.0 \\ 40 & 40.0 \\ 64 & 64.0\end{array}$

After putting the law, it is possible to decrease the number of your medical errors in your work.

Are you satisfied with the law that is applied in your work at the hospital?

There is a law punishments if you commit any medical error in your work.

Medical errors come from not stating and applying the laws in your work at hospital.

Does the law apply to all doctors in your job fairly?

Are there laws in your hospital under discussion?

48.0

67.0

37.0

40.0

64.0

\section{Ethics of doctors}

Based on studying the relation among the malpractice problem and ethics of doctors, around $33.0 \%$ of respondents from the maternity department strongly agreed and that there is a noticed relation among the malpractice and doctors ethics. On the other hand, $36.0 \%$ of respondents from the surgery department agreed that malpractice is related to their ethics, while $40.0 \%$ of them dis-agreed with this issue. The table below presents results of data about ethics of doctors to improve the quality of health care quality.

Table 4: doctor's ethics of the study population $(\mathrm{N}=100)$.

\section{Questions with strongly agree and agree answers}

Ethics are very important in your job.

Your ethics supports patient's choices.

Ethics can improve the quality of doctors practice for the patients.

The law provides professional ethics in your health sector.

All doctors applied professional ethics in your work at the hospital.

There is a different ethics that applied in your job in the hospital.

Professional ethics Interested in how to decent behave during your work in the hospital.

The ethics that put in your work will Respect patients in the hospital.

From your perspective as a doctor, the ethics treat with patients and doctors fairly.
Your ethics will have an effect on the healthcare quality in your hospital.

$\begin{array}{cc}\text { Number } & \% \\ 77 & 77.0 \\ 69 & 69.0 \\ 70 & 70.0 \\ 74 & 74.0 \\ 77 & 77.0 \\ 39 & 39.0 \\ 58 & 58.0 \\ 72 & 72.0 \\ 69 & 69.0 \\ 58 & 58.0\end{array}$

\section{Discussion}

Practically, Jordan provides healthcare services for people within two sectors; public and private. The previously conducted studies demonstrated that in 2010, around $32.3 \%$ of the total expenses of health were supplied by the private sector, while the rest were supplied by the government one. As a percentage of "Gross Domestic Product"(GDP), total spending on health amounted to (8.0\%) in 2010 according to statistics of "World Health Organization" (WHO), surpassing the average level of spending in the Middle East, which amounted to $(4.5 \%)$ of that year [16].

In this study, the respondents were from different hospitals in Jordan both in rural, cities and urban centers. Most of the respondents were from the city with 65.0 percent, there were 25.0 percent of the respondents from the village while 10.0 percent of the respondents were from the urban areas. The respondents were also of different age and experience. There were 38.0 percent who had experienced of 1 to 5 years while 24.0 percent had experienced of 6 to 15 years while 20.0 percent had experienced of more than 15 years while 18.0 percent stated that they only had less than a year of working experience in the health care service provision. Around $39.0 \%$ of the respondents aged 26-35 years where this represents the highest percentage, while $26.0 \%$ and $20.0 \%$ of them aged $36-45$ and 18-25 years, respectively. On the other hand, only $15.0 \%$ of respondents aged above 46 years. This means that most of the respondents were between the ages of 26-35. Furthermore, the majority of respondents were males .

The first part of questionnaire was about the impact of malpractice on health care quality. There were a high number of medical providers who agreed with the fact that malpractice obviously affects the quality of health care. This question was analyzed based on the departments of the health workers where results explored that $52.0 \%$ of respondents from the maternity department and $44.0 \%$ of those from the surgery one agreed that 
the malpractice has major effect on the provided quality of health care.On the other hand, the majority of the respondents from the medical department agreed with this relation among malpractice and health care quality. The second part of the questionnaire concerns the views of health workers on the issue of applying the law and it is effect on malpractice.Results demonstrated that around $51.9 \%$ of the maternity department respondents and $63.0 \%$ of those from the pediatric one strongly agreed and agreed, respectively that the application of the law can efficiently decrease the malpractice problem. On the other hand, only $12 \%$ of respondents from the surgery department disagreed with this relation.

The third part of the questionnaire concerns the relation among the malpractice problem and ethics of doctors. Again based on departments, 33.0 percent of maternity department respondents strongly agreed that the malpractice is obviously related to their ethics. Conversely, in surgery department, 36.0 percent of respondents agreed that relation, while 40.0 percent of them disagreed with this issue.

Concerning the relation among doctors experience and medical errors, around 29.0 percent of respondents from the maternity department did not agree that the low experience of doctors can increase medical errors. Conversely, around63.0 percent of respondents from this department agreed that the inexperience of doctors can lead to various medical errors. Based on these results, it can be concluded that medical errors obviously affect the level of health care services. This means that the government should ensure that the number of generated medical errors by doctors is reduced in most of the country hospitals.

Practically, it was found that the malpractice is considered as an ethical issue. There are many medical officers who can differentiate between malpractice and negligence. Whereas some health providers stated that patients are the reason for malpractice. However, there were a high number of those who did not agree that the education of doctors is one of the reasons for malpractice. Lastly, the majority of doctors in government hospitals under investigation demonstrated that if the law is applied, the malpractice of doctors can be effectively reduced.

According to the analyzed questionnaire results, the main solution for the malpractice problem in government hospitals is the application of strict laws and monetary fines by the ministry of health for doctors. Also, the ministry of health must ensure the experience and efficiency of doctors before they work in any hospital.

In fact, the obtained results of this study were limited by the nature of the sample. The 100 chosen doctors were volunteered to participate in the study. However, a number of doctors have refused to participate in this survey due to their medical conditions. One of the faced problems during conducting this survey is that in the government hospitals, researchers must to wait until new doctors were admitted to complete the needed sample size. Some hospitals were dropped from the study due to the lack of the cooperation with the survey. Thus, the number of government hospitals which participated in this study was five hospitals only.

\section{Conclusion}

The conducted research demonstrated that there were a high number of the medical providers who agreed with the fact that malpractice affects the quality of health care. Most of participants agreed that the application of law can decrease the malpractice problem of doctors. Also, it was explored that there is a strong relationship between the malpractice and ethics of doctors. Whereas most of the participants agreed that the low experience of doctors can increase medical errors.

From the previous results, it could be argued that malpractice affects the level of health care services. Whereas the doctors also stated that patients are usually the reason for malpractice. To avoid making medical errors or malpractice, the hospital administration can improve the experience of their doctors and employees based on increasing the number of training courses each month. If the laws are applied correctly by doctors, specifically in the government hospitals and committed to professional ethics in their jobs, the health care quality can be improved in Jordanian government hospitals.

\section{Acknowledgments}

The Author wants to thank professor zhanchun feng for his guidance and supervision during writing this survey. Also, he wants to thank his parents, wife, wife's family, family's members and who believes that the knowledge is right for everyone.

\section{References}

[1] Breakoff S, Howard M, and BearingPoint I. MEDICAL MALPRACTICE LAW BEST PRACTICES FOR JORDAN, 2008, 10-44.

[2] Kohn L, Corrigan J and Donaldson M. To Err Is Human Building a Safer Health System. Committee on Quality of Healthcare in America, Institute of Medicine, 2000.

[3] HEALTHGRADES, HEALTHGRADES QUALITY STUDY, patient safety in American hospitals, 2004.

[4] Donald P. AMA Past-President, 2004.

[5] Texans against Lawsuit Abuse, Lawsuit Abuse: Patients Are Paying the Price, 2012.

[6] Fed R. State corollaries also provide for such sanctions, Civ. P. 11. 
[7] Michael F. Does Medical Malpractice Deter? The Impact of Tort Reforms and Malpractice Standard Reforms on Healthcare Quality, 2012, 1-2.

[8] Boehm G. Debunking Medical Malpractice Myths: Unraveling the False Premises behind Tort Reform, Yale Journal of Health Policy, Law, and Ethics, 2013, 2.

[9] Quark A. Legal and Ethical Issues in Medical Practice, Including HIPAA, 2004, 57.

[10] Frakes M. Does Medical Malpractice Deter? The Impact of Tort Reforms and Malpractice Standard Reforms on Healthcare Quality, 2012, 27-28

[11] Cannon M. Reforming Medical Malpractice Liability through Contract, Director, Health Policy Studies Cato Institute, $2010,21-22$.

[12] Jennings B, Baily M, Bottrell M and Lynn J. Healthcare Quality Improvement: Ethical and Regulatory Issues, the Hastings Center, 2007, 165-166.

[13] Coulter A and Ellins J. Patient-focused interventions a review of the evidence, 2006, 3-7.

[14] Johnson S. Regulating Physician Behavior: Taking Doctors Bad Law Claims Seriously, 2012, 59-60.

[15] Khammash T, the Jordanian Health Sector, 2012, 3-23. 